

\section{A GOOD LIFE IN A SUSTAINABLE NORDIC REGION}

Nordic Strategy for Sustainable Development 2013-2025

PolitikNord 2019:705

ISBN 978-92-893-5931-3 (PRINT)

ISBN 978-92-893-5932-0 (PDF)

ISBN 978-92-893-5933-7 (EPUB)

http://dx.doi.org/10.6027/PN2019-705

(๖) Nordic Council of Ministers 2019

Layout: Louise Jeppesen

Cover Photo: unsplash.com

Print: Rosendahls

Printed in Denmark

$$
\text { Printed matter }
$$

Nordic co-operation

Nordic co-operation is one of the world's most extensive forms of regional collaboration, involving Denmark, Finland, Iceland, Norway, Sweden, the Faroe Islands, Greenland, and Åland.

Nordic co-operation has firm traditions in politics, the economy, and culture. It plays an important role in European and international collaboration, and aims at creating a strong Nordic community in a strong Europe.

Nordic co-operation seeks to safeguard Nordic and regional interests and principles in the global community. Shared Nordic values help the region solidify its position as one of the world's most innovative and competitive.

\section{Nordic Council of Ministers}

Nordens Hus

Ved Stranden 18

DK-1061 Copenhagen

www.norden.org

Download and order Nordic publications from www.norden.org/nordpub 


\section{A GOOD LIFE IN A SUSTAINABLE NORDIC REGION}

\section{Nordic Strategy for Sustainable Development 2013-2025}

\section{Contents}

4 FOREWORD

7 A NORDIC PERSPECTIVE ON SUSTAINABLE DEVELOPMENT

13 THE NORDIC WELFARE MODEL

21 VIABLE ECOSYSTEMS

29 CHANGING CLIMATE

35 SUSTAINABLE USE OF

THE EARTH'S RESOURCES

43 EDUCATION, RESEARCH AND INNOVATION

49 ANCHORING, IMPLEMENTATION AND FOLLOW-UP

(11) Nordic Council of Ministers

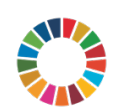




\section{FOREWORD}

In the past year, I have had the pleasure of leading the cooperation in the Nordic Council of Ministers. One of the tasks has been to revise the Nordic Council of Ministers' Strategy for Sustainable Development.

The Nordic Council of Ministers adopted its first strategy 12 years ago. This new strategy, like previous ones, has been approved by all the Nordic countries (Denmark, Finland, Iceland, Norway and Sweden) and the Faroe Islands, Greenland and Åland. The Nordic Council has approved the Strategy for Sustainable Development.

The Nordic Council of Ministers' Strategy for Sustainable Development provides general guidelines for the coming years. Sustainable development involves meeting the needs of present generations without compromising the ability of future generations to meet their own needs. The Nordic countries have consistently common views on key social issues, and the countries agree that social development must be sustainable. 
The Nordic countries have well-developed welfare services, relatively small differences in income, and effective public institutions. The Nordic Council of Ministers will help the Nordic countries to further develop their societies by increasing welfare and improving quality of life. An efficient business community and strong public administration are important elements in this. Preservation and conservation of the environment is also vital for sustainable development. Green growth will help to secure this. Another objective of the Nordic countries is to promote the principles of sustainable development in a global perspective. The Nordic region has a long tradition of working together to develop common solutions to common challenges. The co-operation has brought good results. I am therefore pleased that, with this strategy, the Nordic Council of Ministers has laid a solid foundation for continued close co-operation in the work to attain a sustainable society.

\section{Rigmor Aasrud}

Minister for Nordic Co-operation

Norway

2012

The Nordic Strategy for Sustainable Development was revised in 2019 to reflect its many links to and synergies with the 2030 Agenda. 


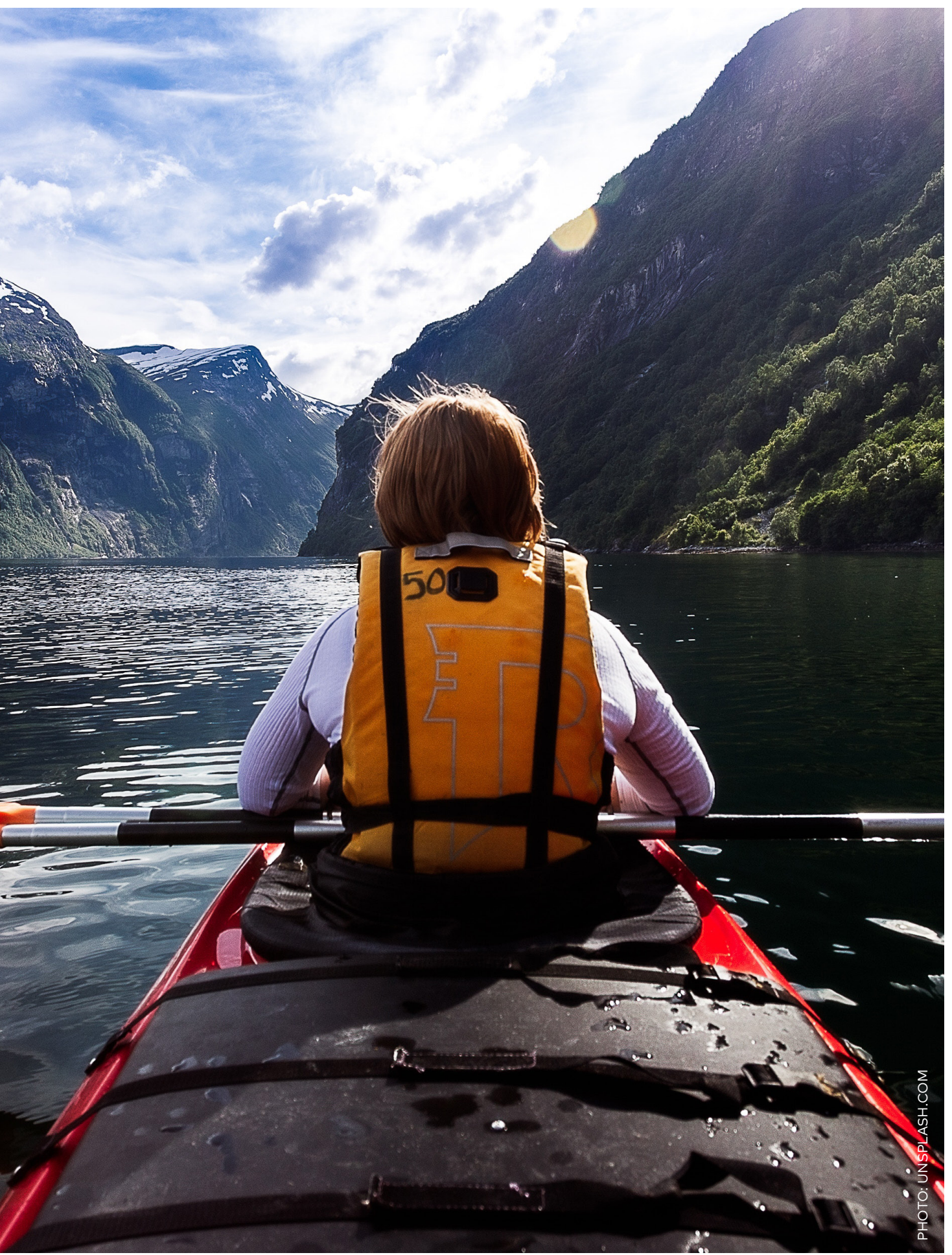




\section{A NORDIC PERSPECTIVE ON SUSTAINABLE DEVELOPMENT}

The Nordic Strategy for Sustainable Development is the overriding and cross-sectoral framework for the work of the Nordic Council of Ministers, and is in line with the ambitions and goals of the 2030 Agenda. There are three interdependent dimensions of sustainable development: the economic, the social and the ecological. One of these dimensions must not undermine the conditions for development in the others. Culture is also very important for the Nordic values. Culture concerns, for example, choice of lifestyle, consumption patterns, relationship to the environment and acceptance of the processes of change in society. Consequently, it is important to include cultural issues in the work on sustainable development.

The Nordic Strategy for Sustainable Development is the overriding and cross-sectoral framework for the work of the Nordic Council of Ministers.
The Nordic countries took a position in sustainable development of society from an early stage. The Nordic welfare model is based on all people having equal value, respect for human rights, justice, equality, good administration, low level of corruption, democracy, and promotion of health and wellbeing. Gender equality, openness and commitment are other important pillars.

The success of the Nordic countries is also a result of affirming, from an early stage, economic openness and free trade. Decades of targeted environmental initiatives have improved the status of the environment in many areas. The Nordic region is rich in natural resources and environment-based sectors such as forestry, agriculture, fisheries and mining. This is important for ensuring vibrant rural areas. To strengthen the economy and sustainable development, it is important that these resources are used but not depleted. Sustainable administration strengthens the economies of the Nordic countries. Stringent requirements on environmental consideration have boosted knowledge and technological development, which in turn have stimulated growing exports of environmental technology. 
People's health and wellbeing are associated with a healthy living environment. The ability to enjoy rewarding leisure time and access to green areas are important ingredients for human wellbeing. It also increases understanding of the measures and changes in behavioural patterns that are needed to make development more sustainable. At the same time, the Nordic countries face more challenges that require crosssectoral measures, where the principle of sustainable development must be integrated. The total ecological foot-

\section{SUSTAINABLE DEVELOPMENT \\ Definition of sustainable development according to the Brundtland Commis- sion: Sustainable development meets the needs of the present generation without compromising the ability of future generations to meet their own needs.}

\section{THE NORDICS}

The Nordic countries are Denmark, Finland, Iceland, Norway, Sweden, the Faroe Islands, Greenland and Åland. print of Nordic activities has increased because of greater consumption. Demographic change is also a key challenge for the Nordic welfare model.

Other challenges include the factors that result from changes in the general economic climate in Europe and the world.

The Nordic Council of Ministers will help the Nordic countries successively continue to improve welfare and quality of life for present and future generations, by protecting and using the earth's ability to sustain life in all its diversity, and thereby develop a more sustainable welfare model. To attain this objective, the Nordic region needs to gradually transform to a green economy. The activities and facilities of the Nordic Council of Ministers and its secretariat will also be sustainable. One option is to obtain environmental certification for the entire organisation, and this could also apply to the Nordic Council and the Nordic Culture Fund.

Green growth has become a key objective that many countries and regions have set up to meet the major environmental, climatic and energy challenges 
while maintaining good economic growth. The market for green solutions is growing, and there is potential for the Nordic region to strengthen its market position. The initiative of the Nordic Prime Ministers for green growth plays an important role in this context. Greater competitiveness and growth will be attained through more effective use of resources, more sustainable use and supply of energy, and more precise legislation about and pricing of natural resources.

\section{Purpose and applicability of the strategy}

The Nordic Co-operation on Sustainable Development was initiated by a Prime Ministers' Declaration in 1998. The first Nordic Strategy for Sustainable Development came into effect in 2001 and has been revised regularly. A new Prime Ministers' Declaration was adopted in 2008, and this is now the fourth Nordic Strategy for Sustainable Development. Following the adoption of the 2030 Agenda for Sustainable Development in 2015, the Nordic Strategy for Sustainable Development was revised to reflect its many linkages and synergies with the 2030 Agenda. It applies until further

\section{GREEN ECONOMY}

The definition of green economy is that used by the United Nations Environment Programme (UNEP): A green economy results in improved human wellbeing and social equity, while significantly reducing environmental risks and ecological scarcities. In its simplest expression, a green economy can be thought of as one which is low carbon, resource efficient and socially inclusive. Practically speaking, a green economy is one whose growth in income and employment is driven by public and private investments that reduce carbon emissions and pollution, enhance energy and resource efficiency, and prevent the loss of biodiversity and ecosystem services. These investments need to be catalyzed and supported by targeted public expenditure, policy reforms and regulation changes. This development path should maintain, enhance and, where necessary, rebuild natural capital as a critical economic asset and source of public benefits, especially for poor people whose livelihoods and security depend strongly on nature. 
notice and will be revised as necessary.

The strategy focuses on areas in which the Nordic countries have common interests and common challenges, and that offer good potential for promoting sustainable development. The Nordic co-operation will also generate added value, and promote greater knowledge and more efficient use of resources. The strategy provides long-term guidelines for the activities of the Nordic Council of Ministers as far as 2025, and is aimed at promoting the cross-sectoral work of the Nordic Council of Ministers in the following focus areas: the Nordic welfare model, viable ecosystems, changing climate, sustainable use of the Earth's resources, and education, research and innovation. The development will be monitored using indicators in each area. Each area is linked to several of the 169 targets under the Sustainable Development Goals, specified at the end of the section.

The common values and objectives of the strategy will be integrated in the sector programmes of the Councils of Ministers, and will be converted into concrete measures with measurable goals. The Councils of Ministers will jointly organise the implementation of the strategy, monitor progress, and assist with reporting and assessment of the implementation. The Nordic Strategy for Sustainable Development can also serve as a basis for joint contributions to international forums on sustainable development.

\section{Overall objectives and principles of the Nordic work on sustainability}

All work done within the framework of the Nordic Council of Ministers will integrate a sustainability perspective. Through Nordic co-operation, the Nordic Council of Ministers will prioritise themes, processes and projects that promote sustainable development. By doing so, the Nordic Council of Ministers can inspire the Nordic countries and other countries and regions to set their own concrete objectives and implement initiatives.

The overall objective of the strategy is for the Nordic countries to gradually develop into more sustainable welfare societies and to bring about positive changes within the foreseeable future. 
The overall objective of the strategy is for the Nordic countries to gradually develop into more sustainable welfare societies and to bring about positive changes within the foreseeable future. By 2025, significant results will have been achieved in the prioritized areas. Present and future generations will be assured a safe, healthy and dignified life. A high degree of awareness will be created in society about the measures and processes that lead to sustainable development.

The Nordic Council of Ministers will promote Nordic co-operation for high employment, green growth and increased competitiveness. The work will be guided by the precautionary principle, the polluter pays principle, producer responsibility, and the substitution principle. In addition, external costs will be increasingly incorporated in the price of products. Indigenous peoples have a special role in sustainable development. These objectives and principles will continue to be integrated in the sector programmes of the Councils of Ministers and in relevant international contexts.

\section{PRECAUTIONARY PRINCIPLE}

If a threat of serious or irreversible damage exists, a lack of full scientific knowledge about the situation may not be used as an excuse to delay cost-effective measures to prevent environmental damage.

\section{POLLUTER PAYS PRINCIPLE}

The polluter pays the cost of pollution.

\section{SUBSTITUTION PRINCIPLE}

When choosing between a product that is better or worse for the environment, the better product will be chosen. In other words, if there is an environmentally better substitute for a product, this must be chosen. 


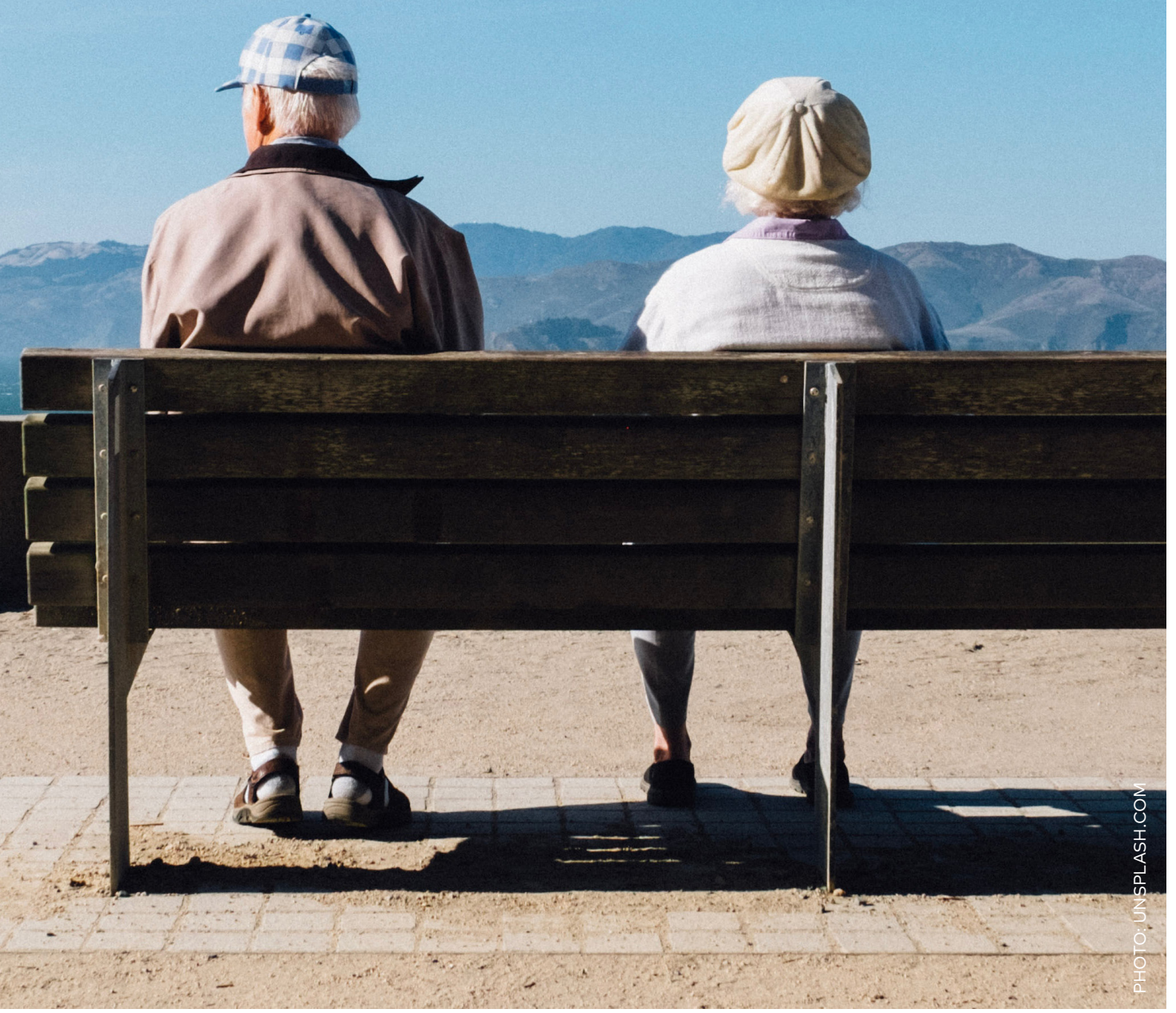




\section{FOCUS AREA 1}

\section{THE NORDIC WELFARE MODEL}

Sustainable development and development of the Nordic welfare model go hand in hand. The Nordic countries have largely succeeded in reconciling ambitious environmental objectives, a high level of income, economic growth, stable national economies and social wellbeing. The social cohesion, public health, effective social insurance, healthy work environment, agreements that regulate salaries and terms of employment, social services, health care, high level of participation on the labour market, and environmental protection, serve as drivers for development, quality of life and security. The Nordic countries have built their welfare models on a common political intention that has created strong cohesion in society. The Nordic model is characterised by a strong relationship between welfare policy and labour market policy. Even if the welfare systems in the Nordic countries are not structured in exactly the same way, the similarities have made the Nordic welfare model a concept.

\section{Sustainable development and development of the Nordic welfare model go hand in hand.}
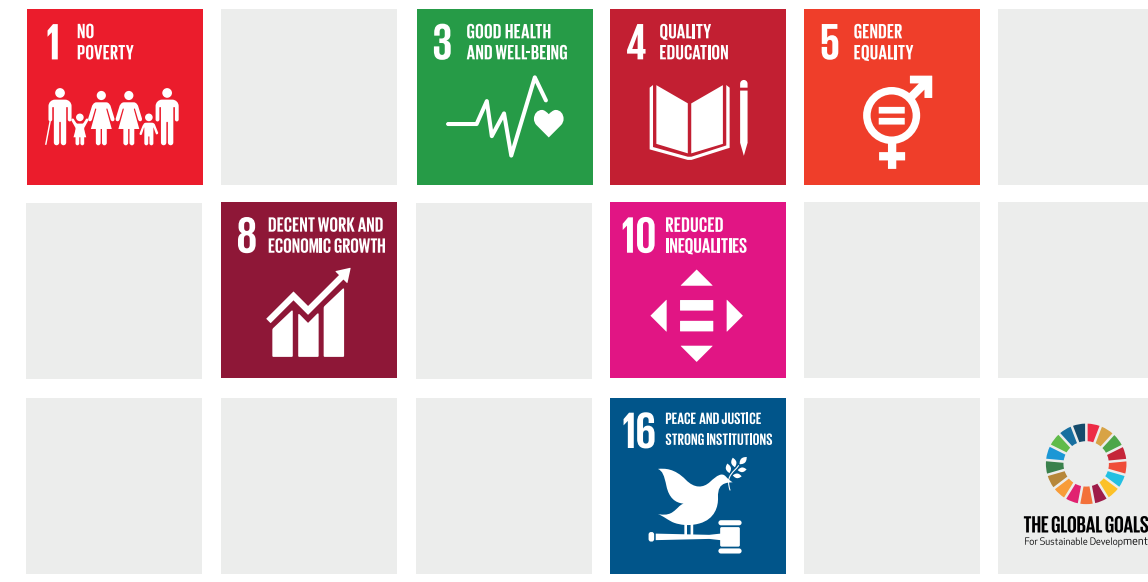
The Nordic social model is known for universal welfare systems. The core values are equal opportunities, social solidarity and security for everyone, regardless of gender, ethnicity, religion, conviction, functional capacity, age and sexual orientation. It concerns social rights and the principle that everyone has equal rights to social and health services, education and culture. It also concerns care for socially disadvantaged and vulnerable groups in society. The welfare model is based on diversity, where all groups are integrated in society. The diversity issue is relevant to most areas in the strategy and should be included in the work on sustainable development. The ability of everyone to participate in society and its decisionmaking processes comprises a key role in the Nordic welfare model. An equal society enables utilisation of all resources in society and, in turn, contributes to better welfare.

\section{The Nordic countries have built their welfare models on a common political intention that has created strong cohesion in society.}

The Nordic welfare model is based on a social structure with good administration, where trust between generations is central. Demographic change in the future is a key challenge, mainly because of the shift in the age structure. One of the most important challenges is to work to ensure that a greater proportion of the working population participate in working life. This means, for example, that the immigrant population needs to be better integrated in social and working life. The transition period from school to work needs to be shortened, and the opportunity to extend working life needs to be improved.

A healthy population is crucial to a sustainable welfare model. The social and demographic challenges make it necessary to strengthen the measures in public health, including prevention of chronic diseases and injuries. Measures are also required to promote active ageing so that more people can maintain functional capacity and look after themselves for as long as possible. A healthy population has a positive influence on the countries' competitiveness, growth and innovative capacity. 
The core values are equal opportunities, social solidarity and security for everyone, regardless of gender, ethnicity, religion, conviction, functional capacity, age and sexual orientation.

Despite relatively strong socio-economic development, poverty also occurs in the Nordic countries. Immigrants, long-term unemployed, people on long-term sick leave, disabled people, and singleparent families are at greatest risk of poverty. Long periods of unemployment among young people are a particularly serious problem, because they risk longterm exclusion from working and social life. Consequently, measures to increase employment among young people are vital.

Another challenge is trafficking in human beings and comparable exploitation that violates the individual's dignity and integrity. In order to be able to stop this development, common knowledge and understanding of this phenomenon are needed. This requires national, regional and international co-operation.

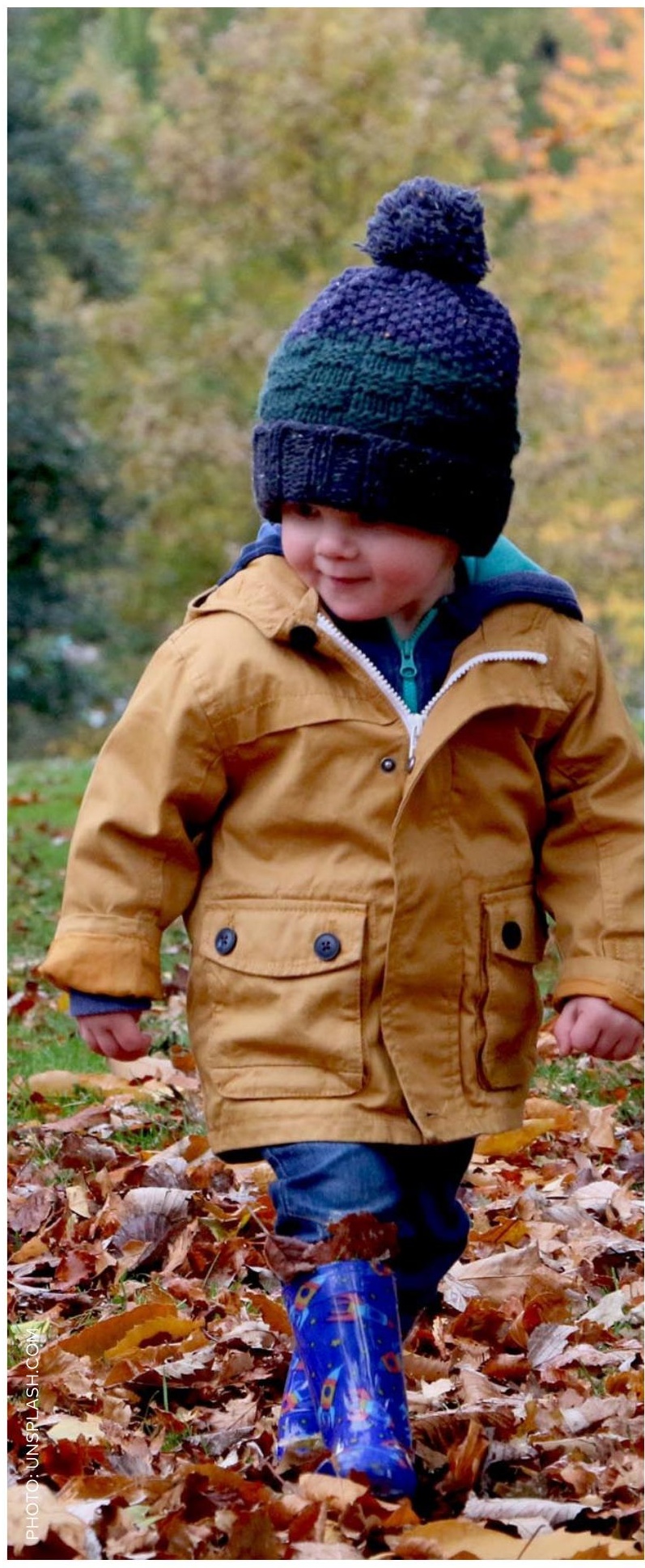




\section{OBJECTIVES UP TO 2025}

\section{Long-term sustainable economic growth}

The Nordic region will have stable, sustainable and healthy economic growth. Sustainability in the financing of the Nordic welfare model will be secured in the light of the demographic development. The Nordic countries will focus on sustainable social planning, based on regional development circumstances.

\section{Work and diversity}

The level of employment and the labour supply in the Nordic countries will increase. The structural unemployment will be reduced, with particular emphasis on unemployment of young people. Inclusion and diversity will be increased in Nordic societies and working life. The level of security, health and welfare in working life will be raised.

\section{Health and social security}

Health and welfare policy will be developed so that the countries retain the social safety net that protects vulnerable groups from exclusion, while securing the competitiveness of the Nordic countries. Quality and security in the social and health sectors will be strengthened. Public health will be improved throughout the population. Preventative measures will be prioritised.

\section{Equality, democracy and human rights} Equality and social cohesion will be promoted with consideration to gender, ethnicity, religion, conviction, functional capacity, age and sexual orientation. Preventative measures will be implemented to promote human rights, for example to eliminate poverty and trafficking in human beings.

\section{Culture}

The significance and role of culture will be identified and strengthened in the work on sustainable development in the Nordic countries.

\section{INDICATORS}

- Demographic trends

- Gross domestic product (GDP)

- Public debt

- Urbanisation

- Employment and unemployment rate

- Life expectancy at birth

- Gini-coefficient

- Risk of poverty amongst families with children

- Gender pay gap 


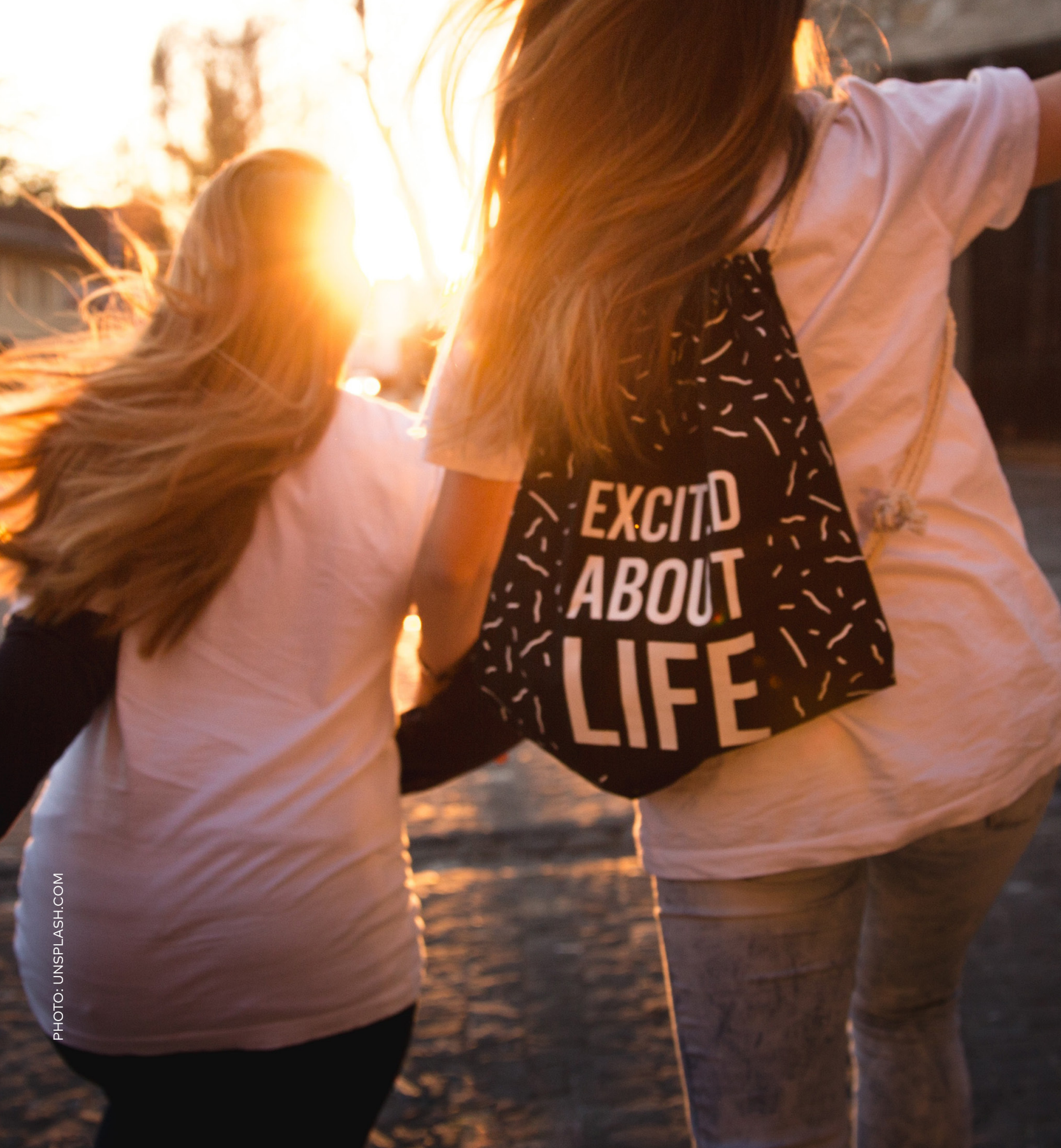




\section{LINKS TO THE SUSTAINABLE DEVELOPMENT GOALS AND TARGETS}
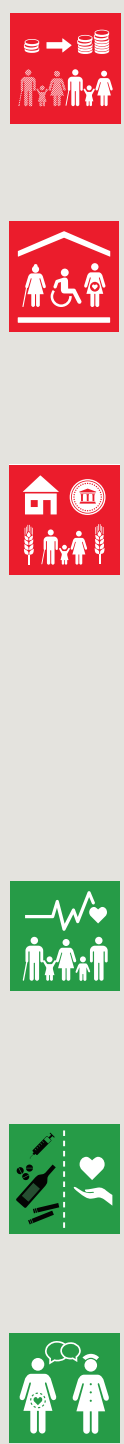

1.2 By 2030 , reduce at least by half the proportion of men, women and children of all ages living in poverty in all its dimensions according to national definitions

1.3 Implement nationally appropriate social protection systems and measures for all, including floors, and by 2030 achieve substantial coverage of the poor and the vulnerable

1.4 By 2030, ensure that all men and women, in particular the poor and the vulnerable, have equal rights to economic resources, as well as access to basic services, ownership and control over land and other forms of property, inheritance, natural resources, appropriate new technology and financial services, including microfinance

3.4 By 2030 , reduce by one third premature mortality from non-communicable diseases through prevention and treatment and promote mental health and well-being

3.5 Strengthen the prevention and treatment of substance abuse, including narcotic drug abuse and harmful use of alcohol

3.7 By 2030, ensure universal access to sexual and reproductive health-care services, including for family planning, information and education, and the integration of reproductive health into national strategies and programmes

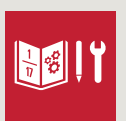

4.3 By 2030, ensure equal access for all women and men to affordable and quality technical, vocational and tertiary education, including university

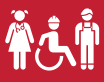

4.4 By 2030, substantially increase the number of youth and adults who have relevant skills, including technical and vocational skills, for employment, decent jobs and entrepreneurship

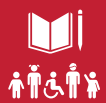

4.5 By 2030, eliminate gender disparities in education and ensure equal access to all levels of education and vocational training for the vulnerable, including persons with disabilities, indigenous peoples and children in vulnerable situations

5.1 End all forms of discrimination against all women and girls everywhere

5.2 Eliminate all forms of violence against all women and girls in the public and private spheres, including trafficking and sexual and other types of exploitation 

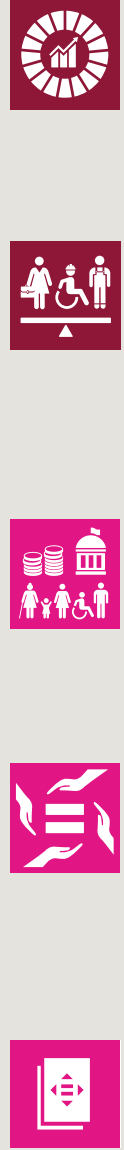

8.1 Sustain per capita economic growth in accordance with national circumstances and, in particular, at least 7 per cent gross domestic product growth per annum in the least developed countries

8.5 By 2030, achieve full and productive employment and decent work for all women and men, including for young people and persons with disabilities, and equal pay for work of equal value

10.2 By 2030, empower and promote the social, economic and political inclusion of all, irrespective of age, sex, disability, race, ethnicity, origin, religion or economic or other status

10.3 Ensure equal opportunity and reduce inequalities of outcome, including by eliminating discriminatory laws, policies and practices and promoting appropriate legislation, policies and action in this regard

10.4 Adopt policies, especially fiscal, wage and social protection policies, and progressively achieve greater equality

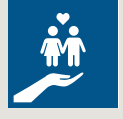

16.2 End abuse, exploitation, trafficking and all forms of violence against and torture of children

$\Delta \backslash \quad$ 16.3 Promote the rule of law at the national and international levels and ensure equal access to justice for all

16.7 Ensure responsive, inclusive, participatory and representative decisionmaking at all levels 


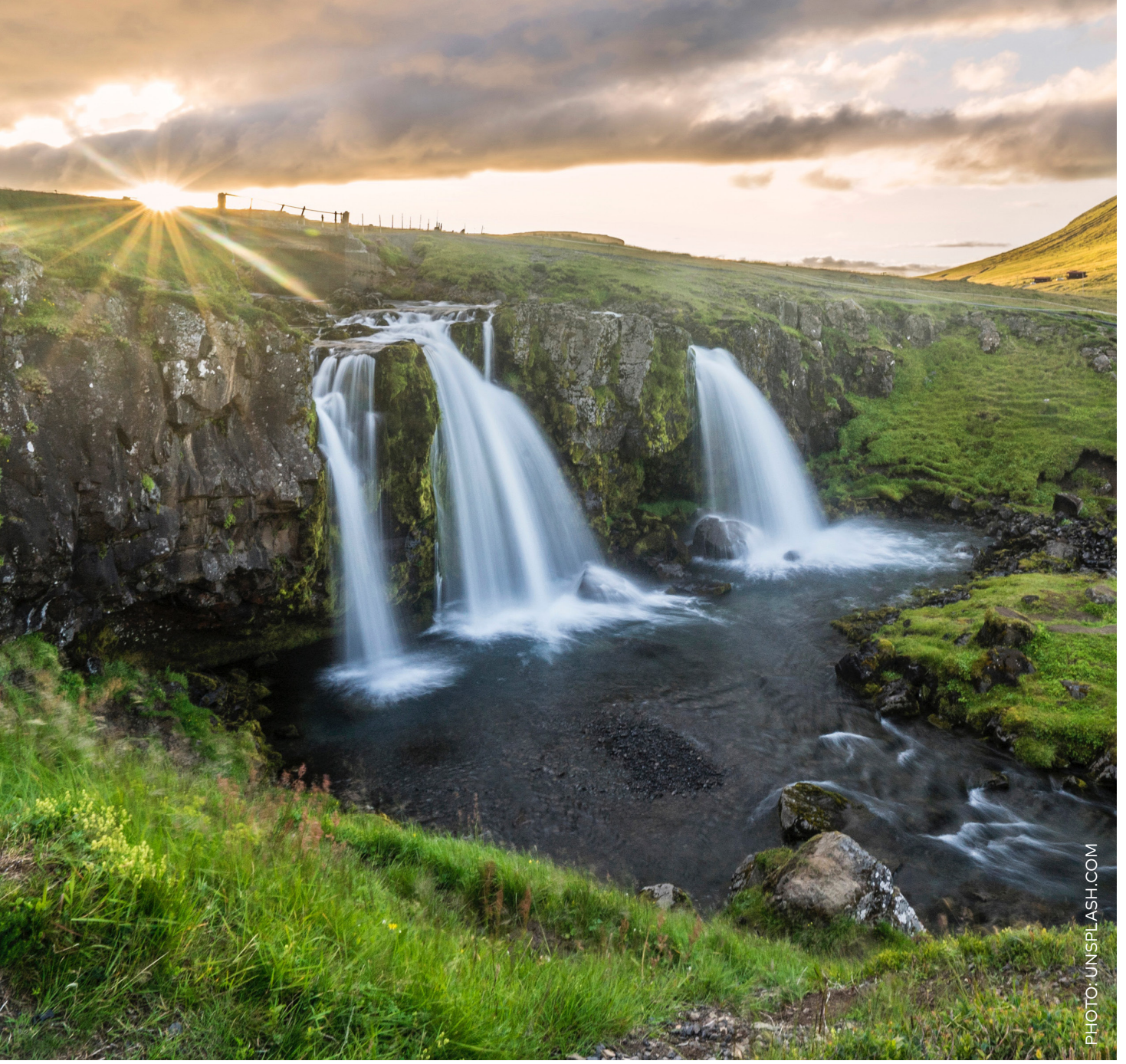




\section{FOCUS AREA 2}

\section{VIABLE ECOSYSTEMS}

The earth's ecosystems provide mankind with a number of vital products and services that enable sustainability and green growth, and human wellbeing. Examples of these ecosystem services are food and other biological raw materials, fresh water, natural water purification, climate regulation, carbon dioxide sequestration, natural protection from environmental disasters, and pollination. Research shows that the status of many ecosystem services has deteriorated considerably. This jeopardises the international community's ability to attain the
Sustainable Development Goals, and has significant effect on industry and human wellbeing.

In 2011-2012, the Nordic Council of Ministers initiated a study with particular focus on the Nordic countries. The study is based on the international report The Economics of Ecosystems \& Biodiversity (TEEB). This identifies the cost incurred when biodiversity and ecosystem services are lost compared with the cost of preserving them. This research emphasises the importance of evaluating ecosystem services and
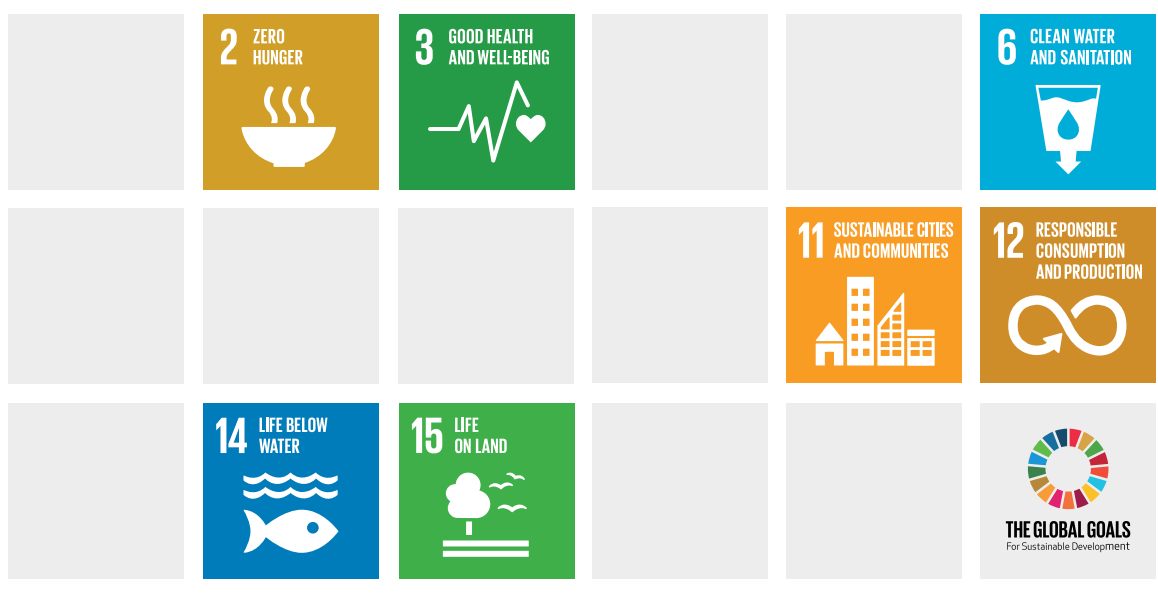
natural resources correctly, and that these costs are integrated in national accounting and in decision-making.

Even if the Nordic region can be regarded as a pioneer in terms of sustainable use of both renewable and non-renewable natural resources, there is great potential for improvement. A key challenge is to develop sustainable operational forms in the various natural and climatic conditions in the Nordic region, while meeting the needs of a growing global population. The biggest ecosystem-related challenges in the Nordic region are that soils and forest are being damaged by pollution and short-sighted management, and that the marine environment is being damaged by discharges from land-based sources of pollution.
A key challenge is to develop sustainable operational forms in the various natural and climatic conditions in the Nordic region, while meeting the needs of a growing global population. 
In order to prevent contamination of the marine environment and coastal areas, it is important to solve the problems at source.

In order to prevent contamination of the marine environment and coastal areas, it is important to solve the problems at source. For example, the Baltic Sea, a virtually land-locked, shallow and cold saline basin, is very vulnerable. It is affected greatly by the massive loading caused by human activities in the countries around its shores. The most serious problem is eutrophication. In addition, high concentrations of hazardous substances, including heavy metals, have been measured. The greatly increased and ever-increasing oil and chemical transports, particularly in the Bay of Finland, also increases the risk of damage to the environment through oil and chemicals. The activity in the Arctic region, with more shipping and transports of oil and gas, means that the Nordic areas in the North Atlantic are exposed to greater environmental risks. Increased work on safety and civil protection policy should therefore be prioritised highly.

\section{ECOSYSTEM SERVICES}

The concept of ecosystem services is based on human needs and wellbeing and so includes the products and services that ecosystems provide. An ecosystem is a collection of plants, animals, and microorganisms that interact with each other and the non-living environment. Ecosystem services can sometimes be confused with biological diversity (biodiversity). Biodiversity concerns the diversity of all living species on earth, i.e. variations within species, and between species and ecosystems. Diversity of species, or biodiversity, is not an ecosystem service. Instead, biodiversity is vital to all ecosystem services. Ecosystem services in turn contribute to biodiversity. 


\section{OBJECTIVES UP TO 2025}

\section{Sustainable management of natural resources}

Biodiversity in the Nordic region will be strengthened so that ecosystems remain robust and continue to provide vital ecosystem services to create welfare. There will be greater knowledge and awareness of the value of ecosystem services, which can help to develop instruments that, in turn, can stimulate sustainable use and preservation of the biodiversity.

\section{Marine ecosystems ${ }^{1}$}

The Nordic marine areas will have a good environmental status and will be used sustainably. Management of the marine areas will be based on knowledge and coherent, ecosystem-based management. Eutrophication of the Baltic Sea will be reduced, and the status of the environment and water areas in the Baltic Sea will be improved.

\section{Land-based ecosystems}

The environmental status of the Nordic land-based ecosystems will be good. An effective balance will be secured between protection and sustainable use of these ecosystems. Sustainable forestry will be secured through protection and management, and consideration will be taken to the diverse functions and ecosystem services of the forest.

Air

Damage to the environment and harm to people caused by air pollution will be reduced. Pollutants will not exceed the permitted limits and international specifications regarding air quality, or the limits that the environment can tolerate. There will be greater knowledge about the association between air pollutants and climate change.

\section{INDICATORS}

- Sustainability of fish stocks

- Discharge of nitrogen and phosphorus to the Baltic Sea

- Changes in the Common Bird Index

- Developments in annual fellings and increment in forests

- Urban population exposure to air pollution by ozone and particulants

1 For marine ecosystems, when linking to the 2030 Agenda target 6.3, we are specifically focusing on the part about improving water quality by reducing pollution and minimizing the release of hazardous chemicals and materials. 


\section{LINKS TO THE SUSTAINABLE DEVELOPMENT GOALS AND TARGETS}
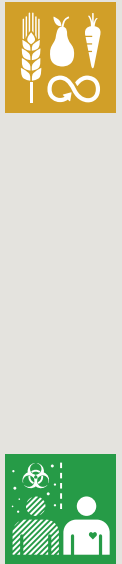

IIIIM

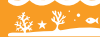

2.4 By 2030, ensure sustainable food production systems and implement resilient agricultural practices that increase productivity and production, that help maintain ecosystems, that strengthen capacity for adaptation to climate change, extreme weather, drought, flooding and other disasters and that progressively improve land and soil quality

3.9 By 2030 , substantially reduce the number of deaths and illnesses from hazardous chemicals and air, water and soil pollution and contamination

6.3 By 2030 , improve water quality by reducing pollution, eliminating dumping and minimizing release of hazardous chemicals and materials, halving the proportion of untreated wastewater and substantially increasing recycling and safe reuse globally

11.4 Strengthen efforts to protect and safeguard the world's cultural and natural heritage

11.6 By 2030, reduce the adverse per capita environmental impact of cities, including by paying special attention to air quality and municipal and other waste management

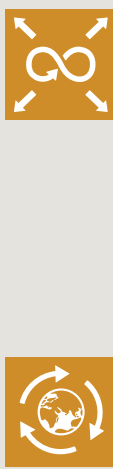

12.1 Implement the 10-Year Framework of Programmes on Sustainable Consumption and Production Patterns, all countries taking action, with developed countries taking the lead, taking into account the development and capabilities of developing countries

12.2 By 2030, achieve the sustainable management and efficient use of natural resources

12.4 By 2020, achieve the environmentally sound management of chemicals and all wastes throughout their life cycle, in accordance with agreed international frameworks, and significantly reduce their release to air, water and soil in order to minimize their adverse impacts on human health and the environment 


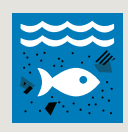

14.1 By 2025, prevent and significantly reduce marine pollution of all kinds, in particular from land-based activities, including marine debris and nutrient pollution

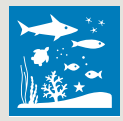

14.2 By 2020 , sustainably manage and protect marine and coastal ecosystems to avoid significant adverse impacts, including by strengthening their resilience, and take action for their restoration in order to achieve healthy and productive oceans

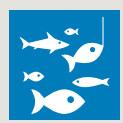

14.4 By 2020, effectively regulate harvesting and end overfishing, illegal, unreported and unregulated fishing and destructive fishing practices and implement sciencebased management plans, in order to restore fish stocks in the shortest time feasible, at least to levels that can produce maximum sustainable yield as determined by their biological characteristics

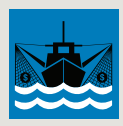

14.6 By 2020, prohibit certain forms of fisheries subsidies which contribute to overcapacity and overfishing, eliminate subsidies that contribute to illegal, unreported and unregulated fishing and refrain from introducing new such subsidies, recognizing that appropriate and effective special and differential treatment for developing and least developed countries should be an integral part of the World Trade Organization fisheries subsidies negotiation
15.1 By 2020, ensure the conservation, restoration and sustainable use of terrestrial and inland freshwater ecosystems and their services, in particular forests, wetlands, mountains and drylands, in line with obligations under international agreements

15.2 By 2020 , promote the implementation of sustainable management of all types of forests, halt deforestation, restore degraded forests and substantially increase afforestation and reforestation globally

15.5 Take urgent and significant action to reduce the degradation of natural habitats, halt the loss of biodiversity and, by 2020, protect and prevent the extinction of threatened species

15.9 By 2020, integrate ecosystem and biodiversity values into national and local planning, development processes, poverty reduction strategies and accounts 


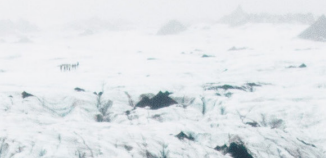

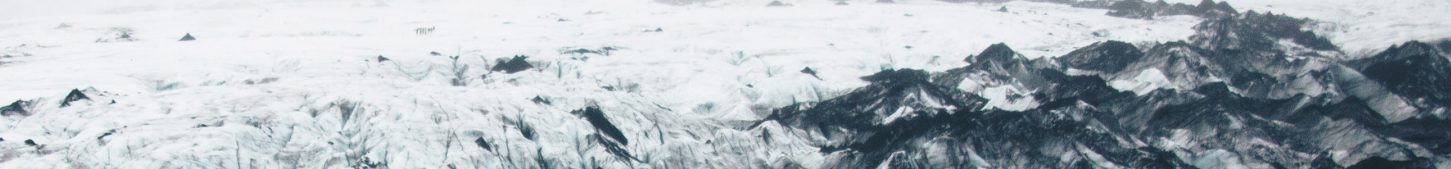

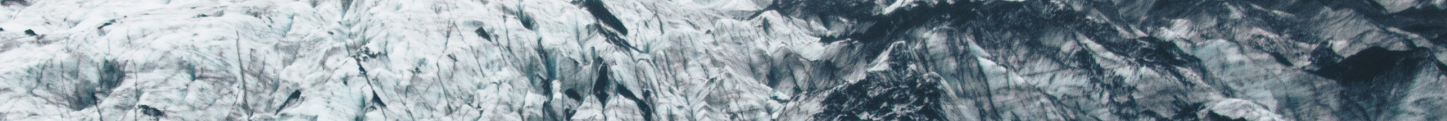

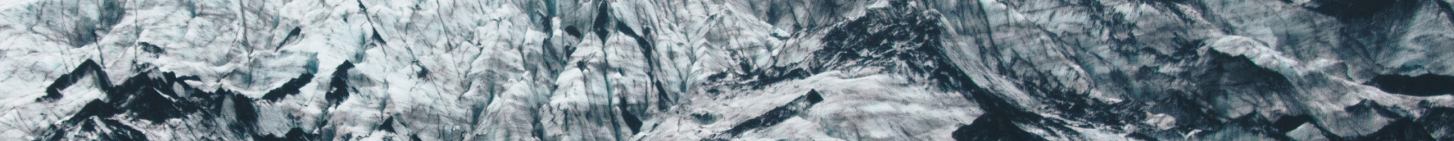

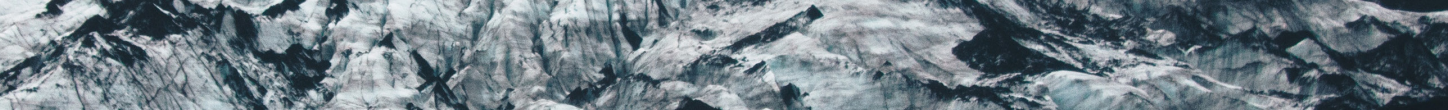

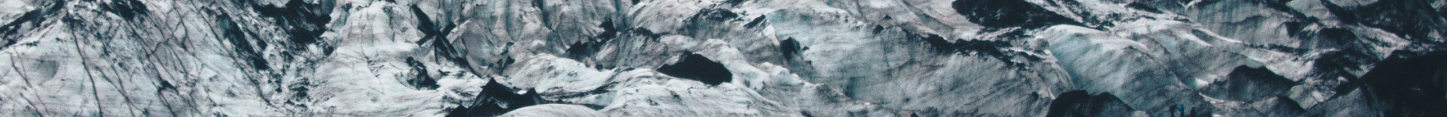

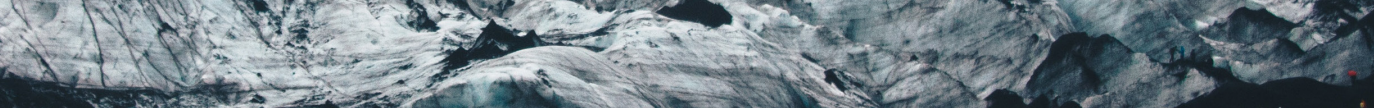

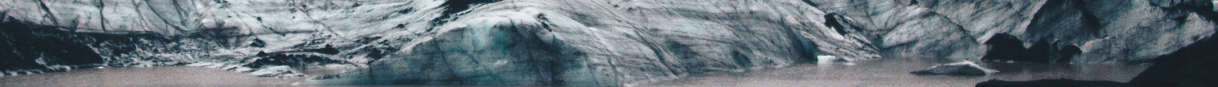

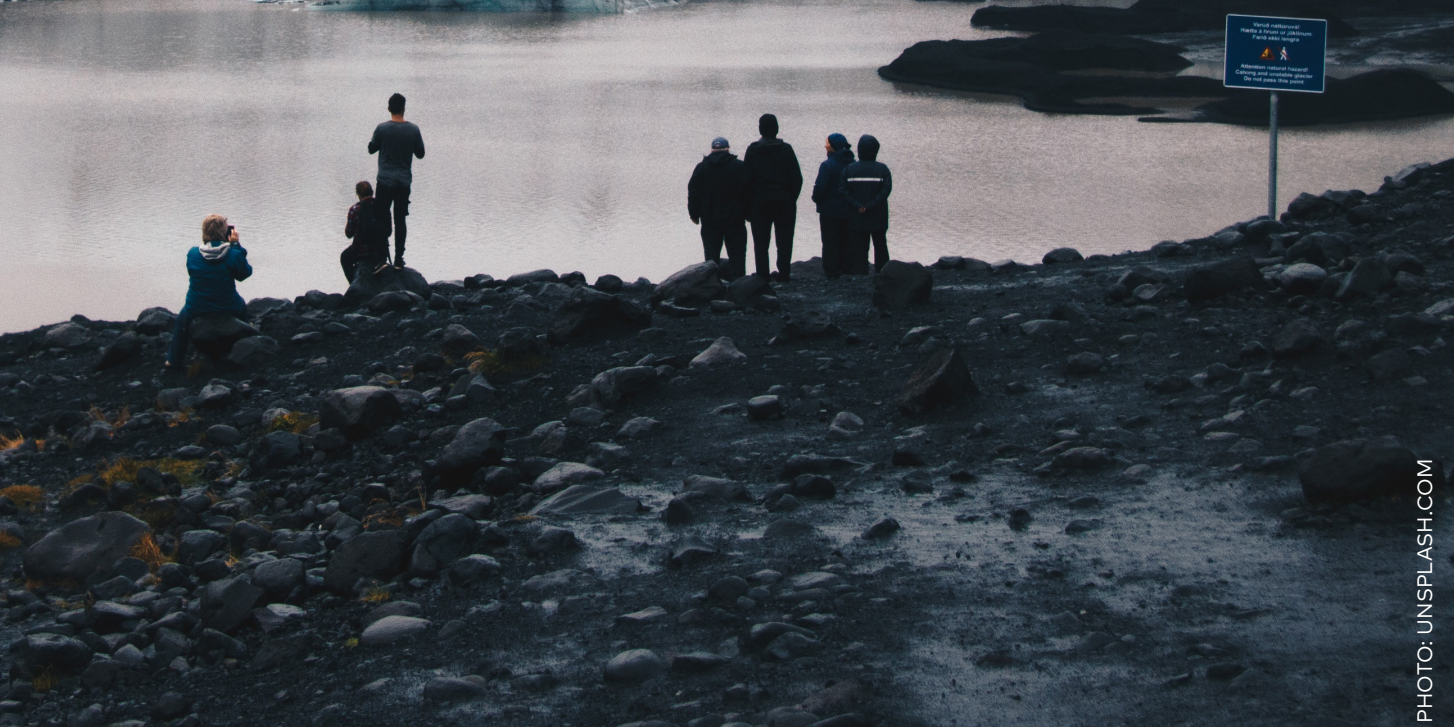




\section{FOCUS AREA 3}

\section{CHANGING CLIMATE}

Climate change is an important challenge that has already had major consequences for mankind and the environment. The United Nations Intergovernmental Panel on Climate Change (IPCC) estimates that the concentration of carbon dioxide (CO2) in the atmosphere will be doubled compared with pre-industrial times. This, in turn, is estimated to lead to an increase in average temperatures of 1.1-6.4 degrees Celsius within a hundred years.

Climate change is expected to have major economic and human consequences, including increased water shortages in certain regions, raised sea levels, more frequent heat waves, more storms, and marine pollution. The risk of disruptions in natural ecosystems and accelerated loss of biodiversity is great, and the welfare of many people will suffer as a result. Within the Nordic region, the effect of climate change is greatest in the Arctic region, which is particularly sensitive.

Climate change has a major effect on the marine ecosystem and the marine resources. The challenges are exacerbated by climate-related ocean acidification, which many researchers believe to be the greatest threat to marine ecosystems. Altered migration patterns
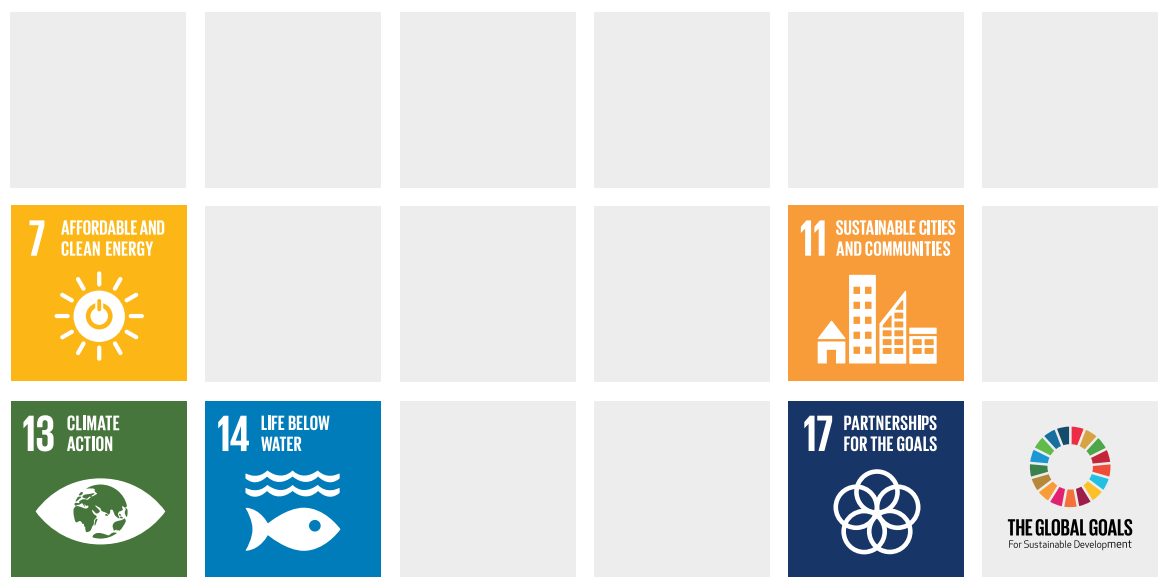
of fish stocks can cause economic, political and management problems. In turn, this requires greater regional co-operation. Climate change also has a negative impact on cities and infrastructure, for example through damage caused by intense rainfall and other extreme weather phenomena - which are expected to increase in the future.

The Nordic countries ${ }^{2}$ have an important role as drivers in the international climate negotiations. The target of the Paris Agreement is to keep the increase in the global average temperature to well below 2 degrees Celsius above pre-industrial levels and pursue efforts to limit the temperature increase to 1.5 degrees Celsius above pre-industrial levels, recognizing that this would significantly reduce the risks and impacts of climate change. This ambitious climate target requires comprehensive and immediate measures in all countries.

The Nordic countries have an important role as drivers in the international climate negotiations.
The link between the use of fossil fuel and economic growth must be broken at global level. Communities and cities need to be adapted to current and anticipated effects of climate change. Adaptation to climate change involves changes in farming methods and land use, including the development of crops and tree species that are more resistant to new types of infectious agents in agriculture and forestry.

But adaptation strategies and mitigation of climate change are not just matters of technology. The social dimension and gender perspective should also be included and considered wherever relevant. In this way, the adaptation strategies can be made more effective and provide better support to the work to mitigate climate change and bring about sustainable development.

Improvements in efficiency in areas such as transport, housing/construction, product development and a transition to a greater proportion of renewable energy are examples of important measures to reduce emissions of greenhouse gases. At the same time, fossil sources of energy are expected to continue to be important

2 In 2016, the Greenland Government, Naalakkersuisut, decided on a territorial reservation for Greenland when Denmark signed the Paris Agreement. 
in the future. Consequently, support is also necessary for measures that help to reduce the use of fossil energy sources and reduce emissions of greenhouse gases, not only within the Nordic region, but also beyond its borders.

Measures for adaptations to the effects of climate change in vulnerable and less developed countries will also be supported. The need for new technological and social innovations can also create opportunities for Nordic businesses.

The link between the use of fossil fuel and economic growth must be broken at global level. Communities and cities need to be adapted to current and anticipated effects of climate change.

The transport sector is important in this context, but because transport is no longer a separate area of co-operation within the work of the Nordic Council of Ministers, the role of the transport sector in sustainable development is not considered in this strategy. 


\section{OBJECTIVES UP TO 2025}

\section{Energy}

Nordic energy supply will be made more sustainable. This will be done through greater focus on renewable energy and more efficient use of energy in the Nordic region. The link between economic growth and consumption of non-renewable energy will be broken. There will be more flexible use of electricity in the Nordic electricity market.

\section{Climate}

The Nordic countries ${ }^{3}$ worked for the production and adoption of the Paris Agreement in 2015 (to come into effect in 2020). The agreement is to keep the increase in the global average temperature to well below 2 degrees Celsius above pre-industrial levels and pursue efforts to limit the temperature increase to 1.5 degrees Celsius above pre-industrial levels. This involves nationally determined contributions (NDCs) to be communicated every five years. The successive NDCs will represent each party's highest possible level of ambition. The Nordic countries will continue to have ambitious national goals for emission reduction within the framework of the Paris Agreement. The role of the Nordic financial institutions in the work on climate and in green investments will be promoted.

The Nordic region will strive to integrate environment and climate issues in development co-operation, and to include welfare and employment aspects in the work on climate.

\section{INDICATORS}

- Share of renewable energy in gross energy supply

- Developments in greenhouse gas emissions by sector

- Emissions and land use, land use change and forestry

3 In 2016, the Greenland Government, Naalakkersuisut, decided on a territorial reservation for Greenland when Denmark signed the Paris Agreement. 


\section{LINKS TO THE SUSTAINABLE DEVELOPMENT GOALS AND TARGETS}
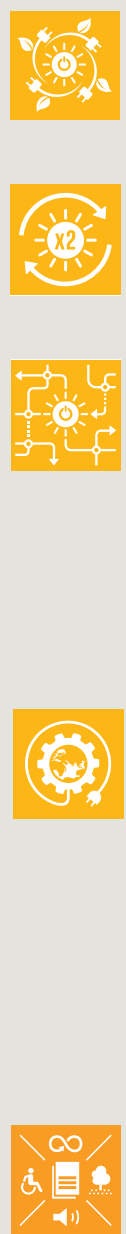

7.2 By 2030, increase substantially the share of renewable energy in the global energy mix

7.3 By 2030, double the global rate of improvement in energy efficiency

7.A By 2030, enhance international cooperation to facilitate access to clean energy research and technology, including renewable energy, energy efficiency and advanced and cleaner fossil-fuel technology, and promote investment in energy infrastructure and clean energy technology

7.B By 2030 , expand infrastructure and upgrade technology for supplying modern and sustainable energy services for all in developing countries, in particular least developed countries, small island developing States and land-locked developing countries, in accordance with their respective programmes of support

11.B By 2020, substantially increase the number of cities and human settlements adopting and implementing integrated policies and plans towards inclusion, resource efficiency, mitigation and adaptation to climate change, resilience to disasters, and develop and implement, in line with the Sendai Framework for Disaster Risk Reduction 2015-2030, holistic disaster risk management at all levels
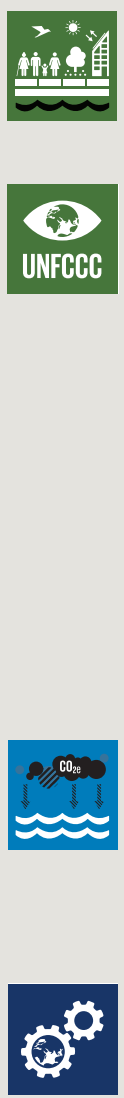

13.1 Strengthen resilience and adaptive capacity to climaterelated hazards and natural disasters in all countries

13.A Implement the commitment undertaken by developedcountry parties to the United Nations Framework Convention on Climate Change to a goal of mobilizing jointly $\$ 100$ billion annually by 2020 from all sources to address the needs of developing countries in the context of meaningful mitigation actions and transparency on implementation and fully operationalize the Green Climate Fund through its capitalization as soon as possible

14.3 Minimize and address the impacts of ocean acidification, including through enhanced scientific cooperation at all levels

17.7 Promote the development, transfer, dissemination and diffusion of environmentally sound technologies to developing countries on favourable terms, including on concessional and preferential terms, as mutually agreed 


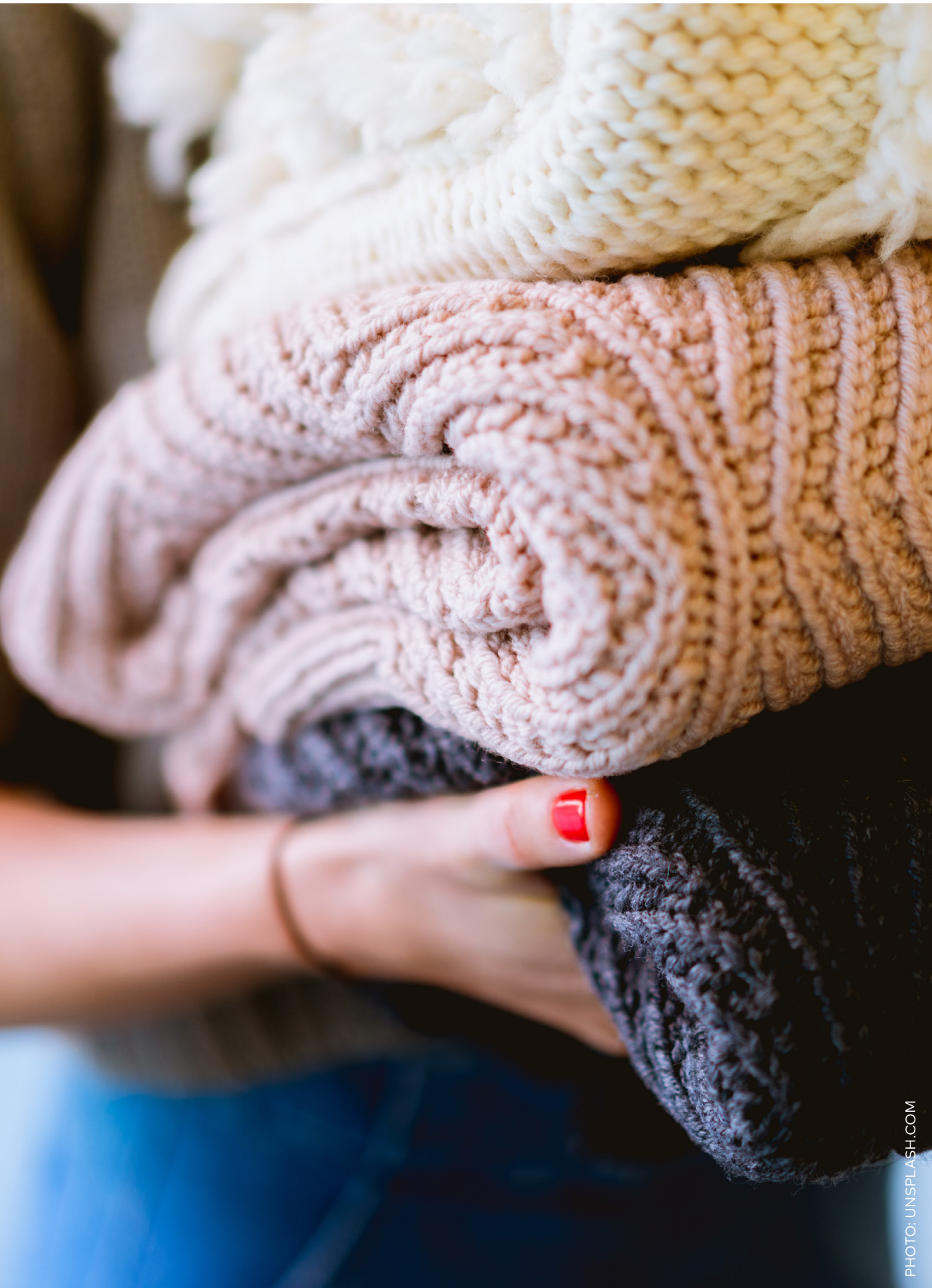




\section{FOCUS AREA 4}

\section{SUSTAINABLE USE OF THE EARTH'S RESOURCES}

Economic growth has enabled high material welfare. At the same time, growth creates significant social and environmental challenges. In many areas, the environmental gains attained through efficient technology have been cancelled out by increased and unsustainable consumption. The problems can often be attributed to lifestyle issues, particularly among the world's wealthier people, where household consumption accounts for approximately half of the environmental impact.
At the global Rio+20 Conference on sustainable development in Rio de Janeiro 2012, a global 10-year framework of programmes was adopted for sustainable consumption and production. This will be very important for future work in this field. It was also in Rio that the decision was made to start initiatives on the Sustainable Development Goals, where natural resource issues and sustainable consumption and production are important themes. Rio +20 also decided to develop indicators that supplement gross domestic product as a measure of development.
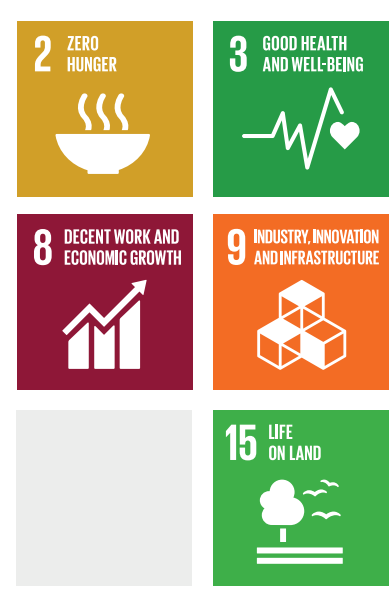

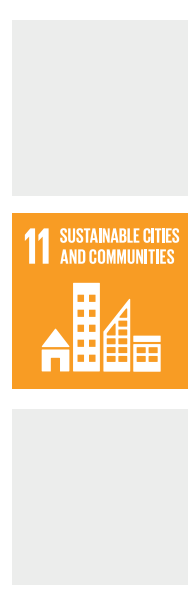

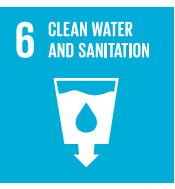
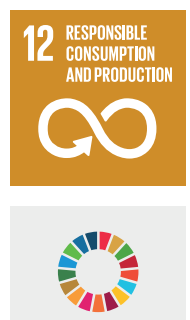

THE GLOBAL GOALS 
The Nordic countries need to reduce the environmental, social and health problems that are associated with unsustainable consumption and production of goods and services.

Even if the Nordic countries have strengthened their environment initiatives, for example through legislation, economic instruments, eco-labelling, and more efficient environment technology, the total ecological footprint has increased. This also applies outside the Nordic borders. Food, housing and transport are areas that particularly influence the environment because they use large amounts of energy and water resources. The Nordic countries need to reduce the environmental, social and health problems that are associated with unsustainable consumption and production of goods and services.

The environmental loading from various foods caused by, for example, animal husbandry, transport and wastage in the food supply chain varies according to product, and may also affect food safety and animal health. Sustainable dietary habits involve observing a number of different perspectives. It concerns, for example, choosing foods with as little negative environmental impact as possible, but that also promote social development and public health. It involves eating safe and nutritious food that reduces overweight, obesity or other lifestyle diseases. It also involves ensuring that production is sustainable. Feeding the world's growing population is a tremendous challenge that the Nordic region should help to resolve.

Demand for and choice of accommodation is affected by the trend in the Nordic countries towards more singleperson households and larger living spaces. Sustainable living assumes efficient use of energy and other natural resources, and also includes health and private economic aspects, safety and accessibility. Sustainable living also requires proximity to workplaces, shops, waste collection, a comprehensive public transport system, pedestrian and cycle networks and other things on which consumers are dependent in everyday life to make sustainable choices. 
In order to promote green growth, it is important to increase the efficiency of resource use, to be economical with finite resources, and to create a new attitude and solution to the waste problem. Waste should increasingly be regarded as a valuable raw material, while waste that contains environmental toxins should be removed from the cycle. Environmental impact from production, goods and waste should be minimized from a life-cycle perspective.

If the Nordic countries act together, initiatives in green growth can attain a greater mass, create a larger market and gain greater political impact in ongoing international processes. Public, private and individual consumers affect the product range through demand, and help to stimulate sustainable products and services. The public sector has a strategic function by ordering sustainable products and services. The business sector also has an important role, for example through greater co-operation with supplier chains in terms of environmental and social aspects, corporate social responsibility (CSR) and environmental labelling.

\section{Environmental impact from production, goods and waste should be minimized from a life-cycle perspective.}




\section{OBJECTIVES UP TO 2025}

\section{Sustainable consumption and production}

The Nordic countries will replace a culture of unsustainable consumption and disposability with a more sustainable re-use culture based on production and consumption adapted to the environment. Sustainable consumption and production will be increased through legislation, economic instruments, information and education, and through infrastructural measures that enable consumers to act in a sustainable way. The work on the Nordic Ecolabel (the Swan) will be developed and strengthened. Nordic co-operation in green technical norms and standards will be extended, including public procurement standards. The Nordic Council of Ministers and its secretariat will have integrated a sustainability perspective throughout its activities.

\section{Resource efficiency and waste ${ }^{4}$}

The Nordic region will break the link between unsustainable use of resources and economic growth through more efficient use of resources, re-use and sustainable waste management.
Negative effects on the environment and health from production, goods and waste in a life-cycle perspective (even in other countries) will have been minimised. Prevention and recovery of waste will be made more efficient, while waste will be increasingly regarded as a valuable raw material. Development of new common technologies and methods will promote more sustainable waste management in the Nordic countries.

\section{INDICATORS}

- Decoupling of environmental pressures, gross energy consumption, resource use and generation of non-mineral waste from economic growth

- Nordic Ecolabel ('the Swan') and the EU Ecolabel

- Proportion of environmental taxes in total tax revenues

- Development in municipal waste generation and in municipal waste management by treatment method

4 For resource efficiency and waste, when linking to the 2030 Agenda targets 6.3 and 6.4 , we are specifically focusing on the parts about recycling and reuse (6.3) and increasing water-use efficiency (6.4). 


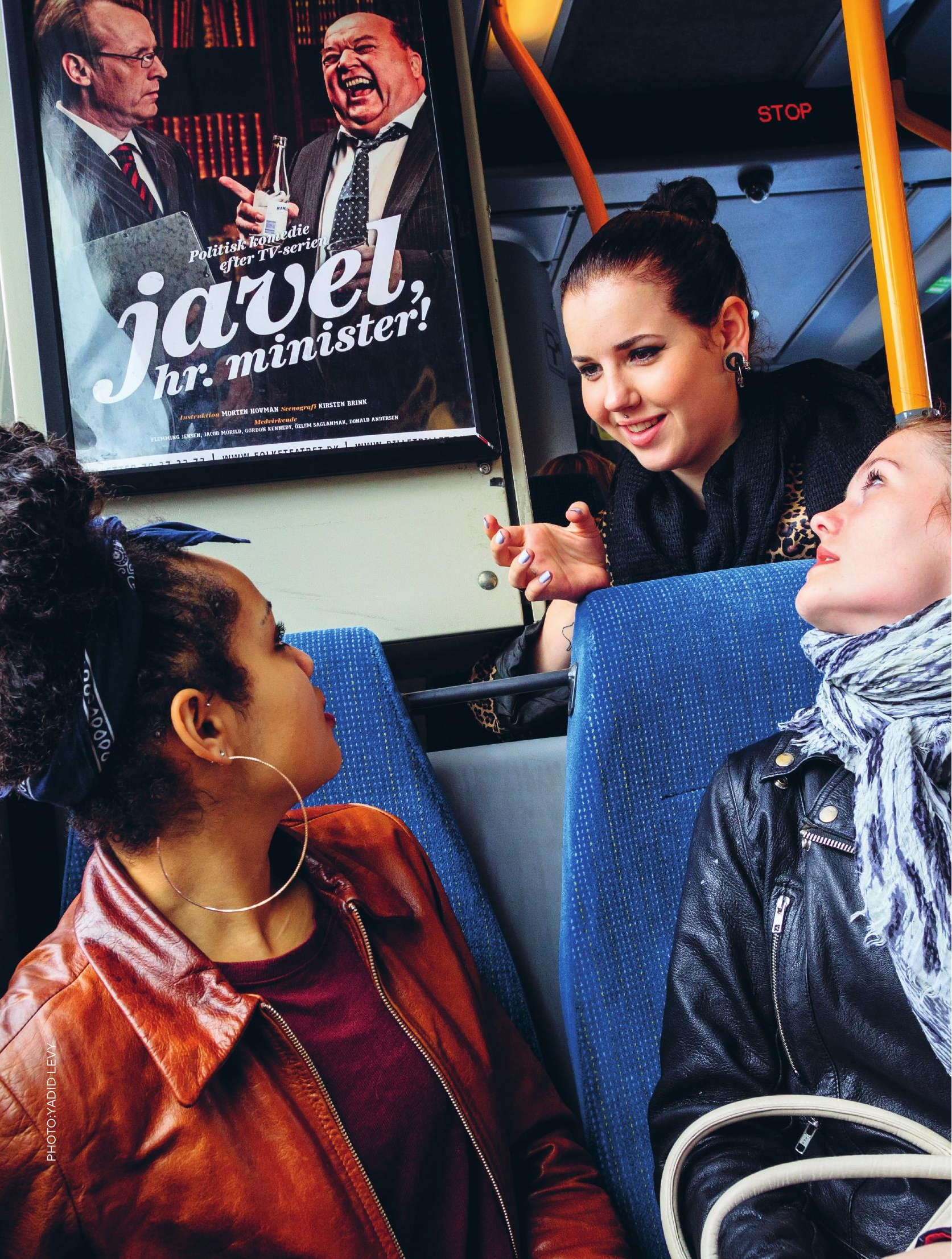




\section{LINKS TO THE SUSTAINABLE DEVELOPMENT GOALS AND TARGETS}
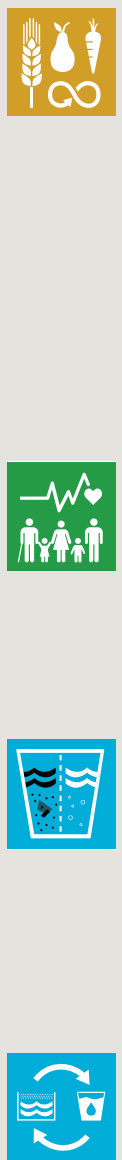

2.4 By 2030, ensure sustainable food production systems and implement resilient agricultural practices that increase productivity and production, that help maintain ecosystems, that strengthen capacity for adaptation to climate change, extreme weather, drought, flooding and other disasters and that progressively improve land and soil quality

3.4 By 2030 , reduce by one third premature mortality from non-communicable diseases through prevention and treatment and promote mental health and well-being

6.3 By 2030, improve water quality by reducing pollution, eliminating dumping and minimizing release of hazardous chemicals and materials, halving the proportion of untreated wastewater and substantially increasing recycling and safe reuse globally

6.4 By 2030, substantially increase water-use efficiency across all sectors and ensure sustainable withdrawals and supply of freshwater to address water scarcity and substantially reduce the number of people suffering from water scarcity

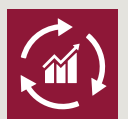

$\mathbf{8 . 4}$ Improve progressively, through 2030, global resource efficiency in consumption and production and endeavour to decouple economic growth from environmental degradation, in accordance with the 10-Year Framework of Programmes on Sustainable Consumption and Production, with developed countries taking the lead

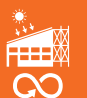

9.4 By 2030 , upgrade infrastructure and retrofit industries to make them sustainable, with increased resource-use efficiency and greater adoption of clean and environmentally sound technologies and industrial processes, with all countries taking action in accordance with their respective capabilities

11.6 By 2030 , reduce the adverse per capita environmental impact of cities, including by paying special attention to air quality and municipal and other waste management

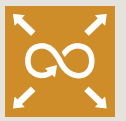

12.1 Implement the 10-Year Framework of Programmes on Sustainable Consumption and Production Patterns, all countries taking action, with developed countries taking the lead, taking into account the development and capabilities of developing countries

12.2 By 2030, achieve the sustainable management and efficient use of natural resources 


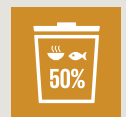

12.3 By 2030, halve per capita global food waste at the retail and consumer levels and reduce food losses along production and supply chains, including post-harvest losses

12.4 By 2020, achieve the environmentally sound management of chemicals and all wastes throughout their life cycle, in accordance with agreed international frameworks, and significantly reduce their release to air, water and soil in order to minimize their adverse impacts on human health and the environment

12.5 By 2030 , substantially reduce waste generation through prevention, reduction, recycling and reuse

12.6 Encourage companies, especially large and transnational companies, to adopt sustainable practices and to integrate sustainability information into their reporting cycle

12.7 Promote public procurement practices that are sustainable, in accordance with national policies and priorities

12.8 By 2030, ensure that people everywhere have the relevant information and awareness for sustainable development and lifestyles in harmony with nature

\section{益目 Q0}

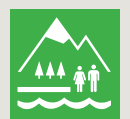

15.1 By 2020, ensure the conservation, restoration and sustainable use of terrestrial and inland freshwater ecosystems and their services, in particular forests, wetlands, mountains and drylands, in line with obligations under international agreements 


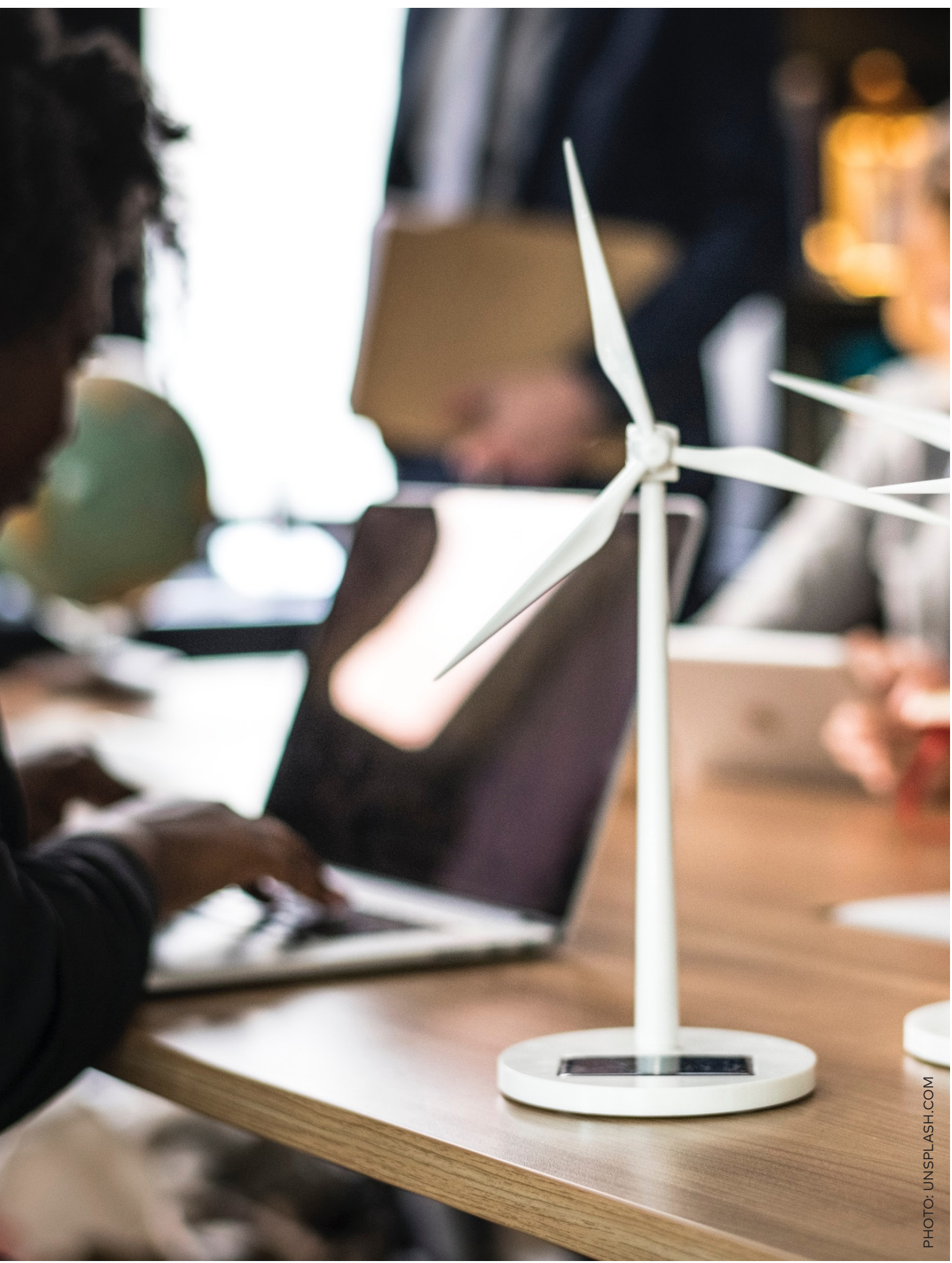




\section{FOCUS AREA 5}

\section{EDUCATION, RESEARCH AND INNOVATION}

Good bases for education, research and innovation are important components for a green economy. Greater knowledge about sustainable development forms the basis for changing attitudes and behaviour in individuals, companies and organisations. Knowledge is required to find solutions to future challenges in the work to attain sustainable development. Knowledge and new technology, but also the ability to use people's competencies, are pillars of Nordic competitiveness and have helped to create internationally successful companies.
A key requirement for developing technology more adapted to the environment is the authorities' possibilities to put a price on and regulate the emissions and discharges of environmentally hazardous substances. This will increase the potential profitability of research and development.

\section{Greater knowledge about sustainable development forms the basis for changing attitudes and behaviour in individuals, companies and organisations.}
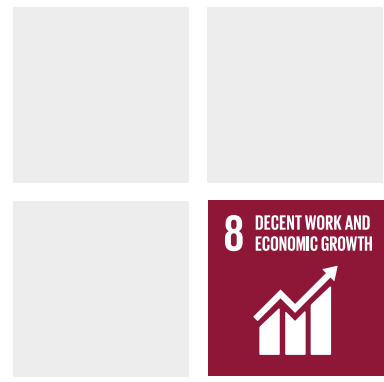
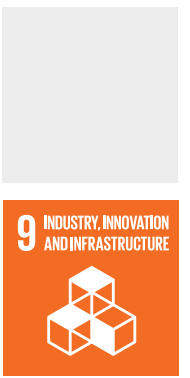
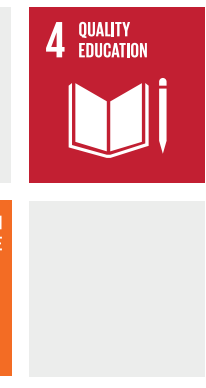
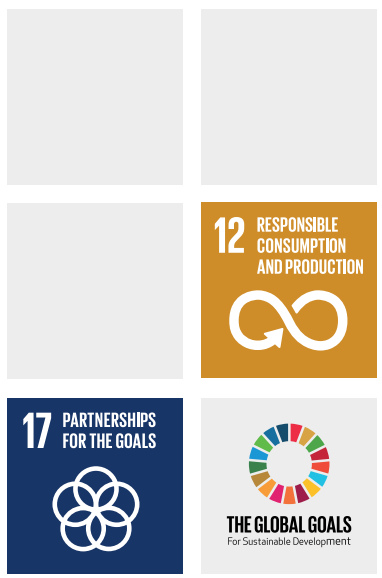

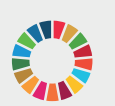

THEGLOBAL GOALS 


\section{Research and innovation environments should be mobilised through investments, and the entire population will have equal access to learning and education of high quality.}

Research and innovation environments should be mobilised through investments, and the entire population will have equal access to learning and education of high quality. The levels of investment in research and innovation will vary between the Nordic countries. The goals that are set up for education about sustainable development will be based on each country's culture and the local social, economic and environmental conditions. Research and innovation environments should be mobilised to address problems of particular relevance for the use of the earth's resources.

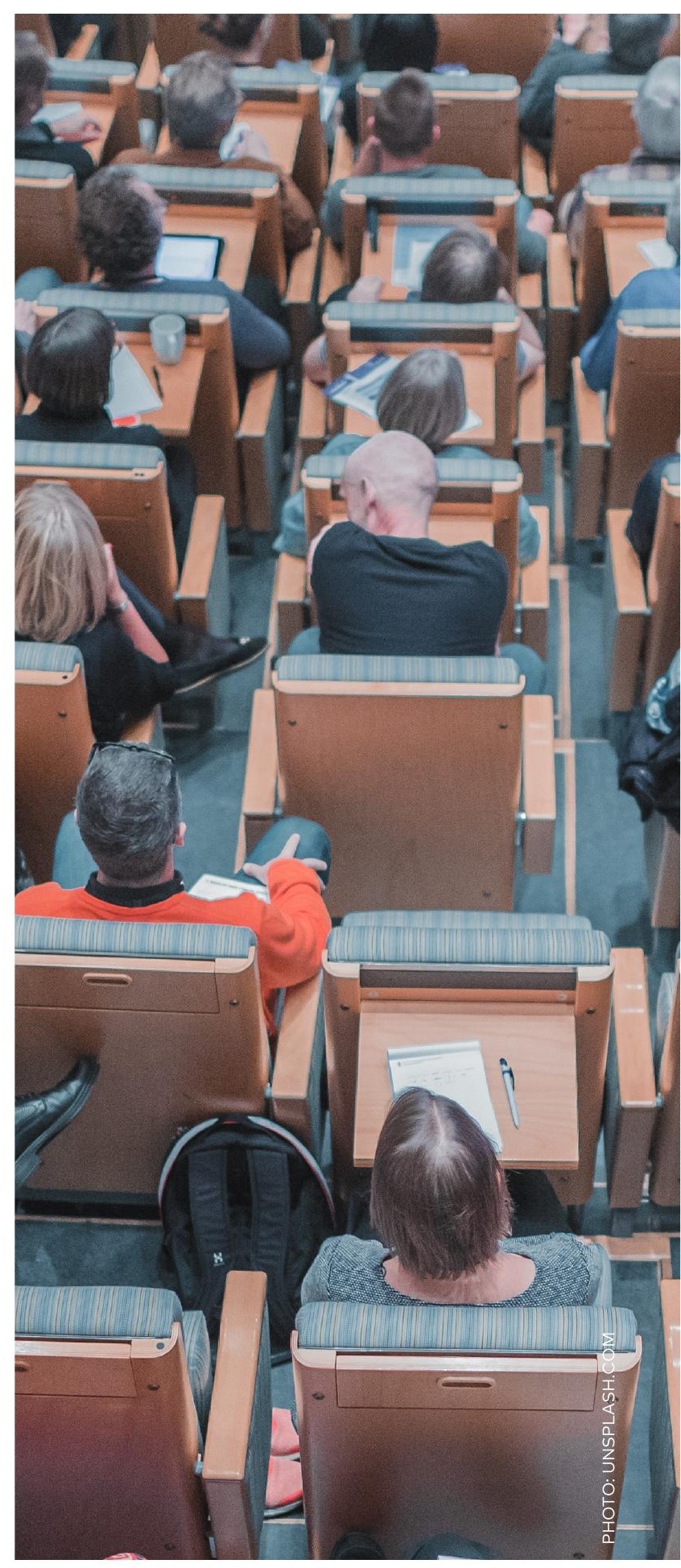




\section{OBJECTIVES UP TO 2025}

\section{Education}

Knowledge about sustainable development will be included in education at all levels. More young people in Nordic countries will study on educational programmes that provide the competencies required by the business community.

\section{Research}

Inter-disciplinary Nordic research and education initiatives will promote sustainable development. This will be carried out in collaboration with similar national and European initiatives, for example in the field of bio-economy. Nordic co-operation will be extended in research and education for green growth, welfare and health. Scientific results will be used more often as the basis of decisions relating to formulation of policies.

\section{Innovation}

The Nordic region will be a leader in terms of development of environmental technology and social innovations to support green growth and sustainable development. Nordic co-operation will be developed in the testing and development of energy technology and the potential for common Nordic test and demonstration facilities will be examined. Financing of green investments and companies will be coordinated and strengthened.

\section{INDICATORS}

- Upper secondary, postsecondary and tertiary education attainment in total population

- Research and development expenditure as a percentage of GDP, by sectors of performance 


\section{LINKS TO THE SUSTAINABLE DEVELOPMENT GOALS AND TARGETS}
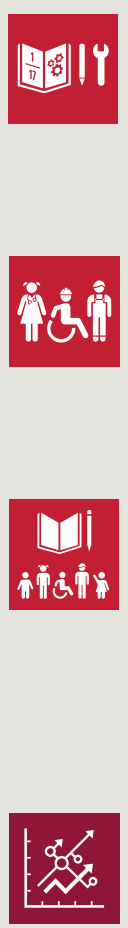

4.3 By 2030, ensure equal access for all women and men to affordable and quality technical, vocational and tertiary education, including university

4.4 By 2030, substantially increase the number of youth and adults who have relevant skills, including technical and vocational skills, for employment, decent jobs and entrepreneurship

4.5 By 2030, eliminate gender disparities in education and ensure equal access to all levels of education and vocational training for the vulnerable, including persons with disabilities, indigenous peoples and children in vulnerable situations

8.2 Achieve higher levels of economic productivity through diversification, technological upgrading and innovation, including through a focus on high-value added and labour-intensive sectors

8.3 Promote development-oriented policies that support productive activities, decent job creation, entrepreneurship, creativity and innovation, and encourage the formalization and growth of micro-, small- and medium-sized enterprises, including through access to financial services
9.5 Enhance scientific research, upgrade the technological capabilities of industrial sectors in all countries, in particular developing countries, including, by 2030 , encouraging innovation and substantially increasing the number of research and development workers per 1 million people and public and private research and development spending

12.8 By 2030, ensure that people everywhere have the relevant information and awareness for sustainable development and lifestyles in harmony with nature

17.7 Promote the development, transfer, dissemination and diffusion of environmentally sound technologies to developing countries on favourable terms, including on concessional and preferential terms, as mutually agreed 


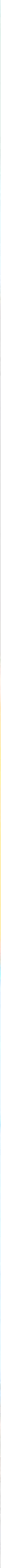




\section{ANCHORING, IMPLEMENTATION AND FOLLOW-UP}

All work done within the framework of the Nordic Council of Ministers will have an integrated sustainability perspective, closely linked to the Sustainable Development Goals. The strategy will form the basis of the budget of the Nordic Council of Ministers and its long-term work on sustainable development.

The Nordic Ministers for Co-operation, through their coordinating and assisting role in relation to the prime ministers, have overall responsibility for coordinating the implementation of the strategy. The Ministers for Co-operation are responsible for information, reporting, evaluation and revision of the strategy. The Nordic Expert Group for Sustainable Development assists the Nordic Ministers for Co-operation in the work on sustainable development.

\section{All work done within} the framework of the Nordic Council of Ministers will have an integrated sustainability perspective.
The objectives of the strategy will be integrated in the sector programmes of the Councils of Ministers, and will be converted to concrete measures with measurable goals.

The strategy will be realised within the various co-operation areas of the Council of Ministers. The objectives of the strategy will be integrated in the sector programmes of the Councils of Ministers, and will be converted to concrete measures with measurable goals. Coordinating with relevant sectors, the Councils of Ministers will jointly organise the implementation of the strategy, monitor progress, and assist with reporting and assessment of the implementation. Sustainable development will also be promoted in collaboration with Nordic institutions and co-operation bodies.

The implementation of the strategy will be financed within the budget framework of the Nordic Council of Ministers. The Councils of Ministers are responsible, within their sector budgets, for financing the implementation, with 
emphasis on the objectives and priori-

tised areas of the strategy.

The allocation of the Nordic Ministers for Co-operation for sustainable development will be used for activities that support the implementation of the Nordic Strategy for Sustainable Development. These initiatives will meet the criteria for Nordic added value, will be cross-sectoral and innovative, and will integrate the three aspects of sustainable development. The funding will also be used to strengthen communication initiatives relating to the Council of Ministers' activities in sustainable development, including the use of the Nordic indicators of sustainable development. The activities will be directed towards the Nordic region, its adjacent areas, and internationally. Through this work, the Nordic Council of Ministers will also contribute to the achievement of the Sustainable Development Goals.
The cross-sectoral co-operation within the Council of Ministers will be supported, for example, by promoting dialogue and exchange of experiences between the sectors relating to the strategy and its objectives, and their importance for each sector. In order to facilitate good communication throughout the Council of Ministers' organisation, and to support more consistent anchoring of sustainability issues, specific contact points will be appointed for each sector. Furthermore, development of new instruments for evaluation, reporting and communication about the results of activities relevant to sustainable development will be considered.

The Nordic indicators of sustainable development will be continually updated. In addition, annual indicator reports will be produced in order to monitor the development in the Nordic region in conjunction with reporting on the implementation of the Nordic Strategy for Sustainable Development. 


\section{NORDIC SUSTAINABLE DEVELOPMENT INDICATORS}

\section{THE NORDIC WELFARE MODEL}

- Demographic trends

- Gross domestic product (GDP)

- Public debt

- Urbanisation

- Employment and unemployment rate

- Life expectancy at birth

- Gini-coefficient

- Risk of poverty amongst families with children

- Gender pay gap

\section{VIABLE ECOSYSTEMS}

- Sustainability of fish stocks

- Discharge of nitrogen and phosphorus into the Baltic Sea

- Change in the Common Bird Index

- Developments in annual fellings and increments in forests

- Urban population exposure to air pollution by ozone and particulates

\section{CHANGING CLIMATE}

- Share of renewable energy in gross energy supply

- Developments in greenhouse gas emissions by sector

- Emissions and land use, land use change and forestry

\section{SUSTAINABLE USE OF} EARTH'S RESOURCES

- Decoupling of environmental pressures, gross energy consumption, resource use and generation of non-mineral waste from economic growth

- Nordic Ecolabel ('the Swan') and the EU Ecolabel

- Proportion of environmental taxes in total tax revenues

- Development in municipal waste generation and in municipal waste management by treatment method

\section{EDUCATION, RESEARCH} AND INNOVATION

- Upper secondary, post-secondary and tertiary education attainment in total population

- Research and development expenditure as a percentage of GDP, by sectors of performance 
Nordic Council of Ministers

Nordens Hus

Ved Stranden 18

DK-1061 Copenhagen

www.norden.org

\section{A GOOD LIFE IN A SUSTAINABLE NORDIC REGION}

Nordic Strategy for Sustainable Development 2013-2025

A Good Life in a Sustainable Nordic Region - Nordic Strategy for Sustainable Development 2013-2025 is the overriding and crosssectoral framework for the work of the Nordic Council of Ministers. All work carried out within the Council of Ministers will incorporate a sustainability perspective.

The Nordic Council of Ministers will help the Nordic countries successively continue to improve welfare and quality of life for present and future generations, by protecting and using the earth's ability to sustain life in all its diversity.

The strategy provides long-term guidelines as far as 2025 in the following focus areas: the Nordic welfare model, viable ecosystems, changing climate, sustainable use of the earth's resources, and education, research and innovation. The sectoral Councils of Ministers will supplement the strategy with concrete measures. 